\section{Commentary: Scimitar syndrome: Cutting through the details}

\author{
Jeremy L. Herrmann, MD, and John W. Brown, MD
}

Vida and Guariento ${ }^{1}$ provide a timely, comprehensive review of pathophysiology, principles of diagnostic evaluation, and considerations for surgical repair for patients with scimitar syndrome. This contribution complements their recent retrospective, multicenter from Europe including 485 patients who were treated medically or surgically across 51 centers. $^{2}$ Using this largest study of its kind, the authors provide a true state-of-the-art assessment of this highly variable clinical entity.

The first surgical correction of scimitar syndrome (although not yet known as this) was reported by Kirklin and colleagues in 1956 for a 32-year-old female patient. ${ }^{3}$ They used a combination of scimitar vein reimplantation and construction of an intracardiac baffle previously described by Bailey and colleagues ${ }^{4} 3$ years previously. It is interesting that these concepts are still the most commonly used techniques for scimitar vein repair.

Based on this review, we understand that scimitar syndrome remains an uncommon condition with variable presentation. Overall survival following surgical correction remains very good, although there is a very real incidence of late scimitar vein stenosis/occlusion following repair. Outcomes inversely relate to patient age, as infants tend to be more symptomatic and exhibit a greater rate of reintervention. Fortunately, many stenoses or obstructions can be managed with transcatheter techniques. Clearly, lifelong cardiology follow-up is very important in these patients.

What remains to be seen is how these patients continue to fare into later adulthood. Furthermore, do different

\footnotetext{
From the Division of Thoracic and Cardiovascular Surgery, Department of Surgery, Indiana University School of Medicine; and Riley Children's Health at Indiana University Health, Indianapolis, Ind.

Disclosures J.W.B.: Teaching honoraria from CryoLife, Inc; Harmony Transcatheter Pulmonary Valve Clinical Events Committee, Medtronic, Inc. The other author has nothing to disclose with regard to commercial support.

Received for publication Dec 11, 2019; revisions received Dec 11, 2019; accepted for publication Dec 12, 2019; available ahead of print Feb 6, 2020.

Address for reprints: Jeremy L. Herrmann, MD, 545 Barnhill Dr, Emerson 215, Indianapolis, IN 46202 (E-mail: jlherrma@iupui.edu).

JTCVS Techniques 2020;1:81

2666-2507

Copyright (c) 2020 The Author(s). Published by Elsevier Inc. on behalf of The American Association for Thoracic Surgery. This is an open access article under the CC BY-NC-ND license (http://creativecommons.org/licenses/by-nc-nd/4.0/)

https://doi.org/10.1016/j.xjtc.2019.12.009
}

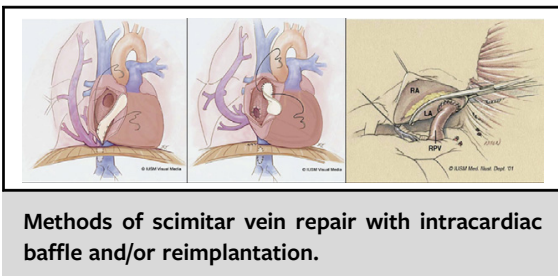

CENTRAL MESSAGE

This state-of-the-art, compre-

hensive review offers detailed insights into the pathophysiology, diagnosis, and surgical management of scimitar syndrome.

techniques confer different outcomes, and not just in terms of overall survival? The authors postulate that, given current data, younger patients may benefit more from an intracardiac baffle versus reimplantation. However, the subtle nuances of the various repairs are difficult to glean from this review and the recent European study. Since 1990, we have favored reimplantation repair using a right thoracotomy, off-bypass approach when no significant atrial septal defect is present. ${ }^{5,6}$ In total, we have treated 18 patients (median age 5.8 years, interquartile range 2.2-37 years), and at a median follow-up of 14 months (interquartile range 2.1-54 months), there have been no mortalities or reinterventions.

Multicenter studies will continue to be needed to generate adequate statistical power for identifying any procedure-related outcomes and long-term risk factors. Hopefully, such concerted efforts will support the development of management guidelines for the treatment of scimitar syndrome.

\section{References}

1. Vida VL, Guariento A. A sword threatening the heart: the scimitar syndrome. J Thorac Cardiovasc Surg Tech. 2020;1:75-80.

2. Vida VL, Guariento A, Milanesi O, Gregori D, Stellin G, Scimitar Syndrome Study Group. The natural history and surgical outcome of patients with scimitar syndrome: a multi-centre European study. Eur Heart J. 2018;39:1002-11.

3. Kirklin JW, Ellis FHJR, Wood EH. Treatment of anomalous pulmonary venous connections in association with interatrial communications. Surgery. 1956;39: 389-98.

4. Bailey CP, Bolton HE, Jamison WL, Neptune WB. Atrio-septo-pexy for interatrial septal defects. J Thorac Surg. 1953;26:184-219.

5. Brown JW, Ruzmetov M, Minnich DJ, Vijay P, Edwards CA, Uhlig PN, et al Surgical management of scimitar syndrome: an alternative approach. $J$ Thorac Cardiovasc Surg. 2003;125:238-45.

6. Gudjonsson U, Brown JW. Scimitar syndrome. Semin Thorac Cardiovasc Surg Pediatr Card Surg Annu. 2006;9:56-62. 